\title{
Participação e experiência estética em Do corpo à terra e Objeto e participação
}

\section{Participation and aesthetic experience in Do corpo à terra and Objeto e participação}

\author{
Tamara Silva Chagas \\ Doutoranda em História, Universidade Federal do Espírito Santo \\ tamara.chagas1@gmail.com
}

CHAGAS, Tamara. Participação e estética em Do corpo à terra e Objeto e participação. História, histórias, vol. 8, no 15, jan./jun. 2020. http://dx.doi.org/10.26512/rhh.v8vi15i.24644

Resumo: Idealizadas pelo crítico de arte Frederico Morais, a manifestação Do Corpo à Terra e a exposição Objeto e Participação foram propostas como dois eventos paralelos e inter-relacionados. O caráter experimentalista e a radicalidade das proposições artísticas integrantes das mostras tornaram ambas realizações memoráveis, que desafiaram a censura e a perseguição política vigente em 1970. Propomos, neste artigo, tecer uma reflexão acerca desses eventos à luz da ideia de arte como participação e experiência. Nossa conclusão é que Do Corpo à Terra e Objeto $e$ Participação tiveram o importante papel de estimular a experiência do espectador, transformandoo em colaborador do processo criativo, além de contribuir para a diluição da arte no âmbito da vida.

Palavras-chave: Do Corpo à Terra; Objeto e Participação; Experiência; Participação; Arte brasileira.

Abstract: Idealized by the art critic Frederico Morais, the exhibitions Do Corpo à Terra and Objeto e Participação were proposed as two parallel and related events. The experimentalism and the radicalism of the artworks shown at the exhibitions made them both memorable art events, which challenged the current censorship and the political persecution in 1970. In this article we propose to reflect on these events according to the idea of art as participation and experience. Our conclusion is that Do Corpo à Terra and Objeto e Participação had an important role encouraging the spectator's experience, turning him into a collaborator of the creative process, also contributing to the dissolution of art in life's context.

Keywords: Do Corpo à Terra; Objeto e Participação; Experience; Participation; Brazilian art. 


\section{Introdução}

Em abril de 1970, foram abertas duas exposições de relevância inquestionável para a historiografia da arte brasileira: Do Corpo à Terra e Objeto e Participação. Ambas as mostras foram idealizadas e organizadas pelo crítico de arte, artista e organizador de exposições mineiro Frederico Morais - à época assim chamado, posto que o termo curador ainda não era usado no Brasil. Muitas pesquisas atuais destrincham esses importantes eventos. Aqui, porém, buscamos estudá-los a partir de uma abordagem que considere o aspecto da participação do espectador e da experiência estética. Para tanto, faremos uma breve referência ao pensamento do filósofo estadunidense John Dewey. Concluímos que Do Corpo à Terra e Objeto e Participação tiveram como mérito a reafirmação da experiência do espectador, trazendo novamente à tona sua importância no contexto da arte.

\section{Conceitos relevantes a respeito das mostras}

As duas exposições foram simultâneas, mas tinham como particularidade conceitos diferentes. Enquanto Objeto e Participação dava ênfase ao objeto como nova categoria artística, Do Corpo à Terra abria espaço para propostas de arte desmaterializada, como happenings. Em comum, no entanto, estava o esforço em trazer ao primeiro plano a participação do espectador. Nesse sentido, é válido destacar que, enquanto o primeiro se deu no âmbito do ambiente institucional museológico, a saber, no Palácio das Artes (Belo Horizonte, Minas Gerais), o segundo ocorreu no Parque Municipal desta cidade - onde se situa a instituição -, nas ruas da capital mineira e também em outras localidades próximas, como a região da Serra do Curral, na zona rural.

As duas mostras tinham também em comum o fato de se constituírem ambientes abertos a trabalhos artísticos experimentais, em um momento em que o conceito de obra, como objeto estético de valor cultual, era questionado. Os novos artistas brasileiros que propunham uma renovação nas artes plásticas no contexto local, em diálogo com a produção internacional, encontraram nas exposições citadas espaços democráticos para o novo tipo de arte que faziam. Nesse sentido, Do Corpo à Terra e Objeto e Participação foram duas das mais relevantes mostras brasileiras pensadas a partir da ideia de uma 
(re)significação do conceito de arte e de obra como algo aberto à participação e, muitas vezes, desmaterializado.

Além de discutir temas novos e relevantes à época para o contexto artístico, as exposições e, principalmente, Do Corpo à Terra, abrigaram propostas radicais não apenas por seu experimentalismo estético, mas igualmente pela contestação da conjuntura sociopolítica do período. Vale lembrar que vivíamos os tempos da Ditadura Militar brasileira desde o golpe ocorrido em março de 1964. Estávamos no auge da repressão. 0 Ato Institucional № 5 acabara entrar em vigor, em dezembro de 1968. O decreto aumentava o cerceamento à liberdade de expressão e institucionalizava a tortura de opositores do governo e dos chamados subversivos, entre os quais estavam muitos artistas e intelectuais.

Vários dos trabalhos apresentados em Do Corpo à Terra e Objeto e Participação tinham esse viés contestatório, como as trouxas ensanguentadas de Artur Barrio e os carimbos de Thereza Simões. Em ambos os casos, é importante destacar, são problematizadas concomitantemente questões inerentes à arte e ao âmbito da vida social e política do momento, em um esforço em amalgamá-las, trazendo à tona a experiência estética do espectador e devolvendo o objeto artístico a seu contexto original, isto é, a vida cotidiana.

É válido discutir como se deu a inserção das reflexões de Frederico Morais sobre a arte de vanguarda e o papel da crítica em ambas as exposições. Ele foi responsável por abrir espaço em tais mostras e em outras anteriores e posteriores para artistas da nova geração, empenhados em fazer uma arte de vanguarda, experimentalista e, em muitos casos, engajada. Morais defendia uma crítica de arte criativa e aberta em contraposição àquela judicativa e tradicional. Percebia o espectador como co-criador da obra, participante do processo criativo, sendo o artista apenas quem "dá o tiro" ${ }^{1} \mathrm{O}$ crítico deixa de ser uma voz autoritária a fixar um sentido único para a arte, tornando-se o produtor de um discurso em meio a outros de igual valor, como os do artista e do público.

Assim, entra em crise a perspectiva do museu como lugar sancionador do juízo da crítica convencional e templo em que se guarda a obra como objeto aurático e retirado de seu contexto de origem. Isso significa que a instituição museológica tradicional legitima o

\footnotetext{
${ }^{1}$ MORAIS, F. Artes plásticas: a crise da hora atual. Rio de Janeiro: Paz e Terra, 1975, p. 26.
} 
afastamento do observador da experiência estética e da sua efetiva participação no processo criativo. O museu como "cubo branco" apresenta-se como um local higiênico e sagrado $^{2}$, apartado da vida cotidiana e, desse modo, conserva obras como itens místicos ou religiosos, inibindo a participação do espectador, resumindo-a em uma contemplação passiva.

\section{Objeto e participação}

Segundo o website do Instituto Itaú Cultural, integraram Objeto e Participação trabalhos dos artistas Carlos Vergara, Franz Weissmann, George Helt, Guilherme Vaz, lone Saldanha, Ivone Etrusco Junqueira, José Ronaldo Lima, Manoel Serpa, Marcello Nitsche, Nelson Leirner, Odila Ferraz, Orlando Castaño, Thereza Simões e Umberto Costa Barros. Acrescentamos que, conforme Marília Andrés Ribeiro ${ }^{3}$, também participaram da mostra Manfredo de Souzanetto e Teresinha Soares. Frederico Morais, consoante já mencionamos, foi seu organizador.

Mari'Stella Tristão, então diretora do Palácio das Artes, foi quem convidou Morais a organizar uma exposição em comemoração à inauguração do centro cultural, durante a chamada Semana de Arte de Vanguarda, contando com o financiamento do governo mineiro e da Hidrominas. ${ }^{4}$ De tal forma, o crítico idealizou Objeto e Participação e Do Corpo à Terra como duas exposições simultâneas, sendo que a última duraria apenas alguns dias: de 17 a 21 de abril de 1970. Já Objeto e Participação, aberta no dia 17, teve duração de um mês. Ambas trariam a experiência do espectador ao primeiro plano, mas uma ocorreria dentro do ambiente museológico enquanto a outra seria uma mostra de arte pública, composta por obras efêmeras e desmaterializadas. Objeto e Participação trazia em si a noção de obra como objeto aberto à participação, à espera de seus desdobramentos a partir da interação com o espectador, em diálogo com exposições que também trouxeram à tona essa questão, como Nova Objetividade Brasileira, de abril de 1967. No contexto desta pesquisa, selecionaremos apenas alguns dos trabalhos participantes da mostra para comentar.

\footnotetext{
2 O'DOHERTY, B. No interior do cubo branco: a ideologia do espaço na arte. São Paulo: Martins Fontes, 2002, p. XIII.

${ }^{3}$ RIBEIRO, M. A. Neovanguardas. Belo Horizonte: C/ Arte, 1997, p. 147.

${ }^{4}$ RIBEIRO, M. A. Neovanguardas..., p. 147.
} 
Thereza Simões participou da exposição com uma série de carimbos, os quais, conforme ela, proporcionavam-Ihe versatilidade e agilidade de comunicação. A artista usou em tais carimbos expressões em inglês e alemão, como: dirty, silent way, fragile, verboten e act silently, sendo que esta última é uma palavra de ordem de Malcolm X, líder radical da luta contra o racismo nos Estados Unidos, assassinado em 1965. É evidente a ligação do trabalho de Simões com seu contexto sociopolítico. Dada a forte censura promovida pela Ditadura à época, muitos dos artistas e intelectuais foram obrigados a encontrar formas alternativas de expressão para fugir do silêncio imposto às vozes dissonantes e, portanto, subversivas.

Paulo Reis ${ }^{5}$ afirma que o fato de Thereza Simões ter usado seus carimbos para marcar as paredes, vidraças e painéis da galeria ressaltou a não neutralidade da arte e do espaço museológico. Tal ação da artista, pensamos, problematizou a pretensa imparcialidade da instituição, revelando a ideologia de passividade intrínseca a ela por força da tradição. O diálogo da artista com o contexto nacional e internacional repressivo buscava instigar no espectador a reflexão sobre a conjuntura em que se encontrava, relacionando arte à vida e, assim, trazendo a primeira novamente às suas origens.

George Helt, por sua vez, depositou uma faixa de papel com pegadas impressas na entrada do Palácio das Artes, num convite aos visitantes da mostra para participarem do trabalho, por meio do caminhar sobre tais pegadas. ${ }^{6}$ Outro artista que dialogou com o público por meio de sua obra foi José Ronaldo Lima, que apresentou "Caixas Olfativas". Eram nove recipientes longos de madeira com diferentes essências em seu interior, tais como: pimenta-do-reino, coentro, jasmim, fumo, sassafrás, orégano, erva-doce, funcho e violeta. O espectador deveria, logo, cheirar o objeto em questão, ativando deste modo o sentido do olfato, tradicionalmente preterido em prol da visão. Tal trabalho parece trazer à tona a procura por uma reconfiguração da hierarquia perceptiva à qual nós - ditos ocidentais - estamos condicionados. A visão é, nesse ínterim, o sentido mais verossímil e puro, estando mais próxima do pensar que os demais, sendo, portanto, menos corrompido. Lima rompe com essa tradição do olhar ao passo que promove uma ruptura com a postura contemplativa e passiva do espectador, incentivando-o a despertar seus sentidos e a agir

\footnotetext{
${ }^{5}$ REIS, P. Exposições de arte: vanguarda e política entre os anos 1965 e 1970. Tese (Doutorado em História) - Setor de Ciências Humanas, Letras e Artes, Universidade Federal do Paran, Curitiba, 2005, p. 185.

${ }^{6}$ MORAIS, F. Do corpo à terra: um marco radical na arte brasileira. Belo Horizonte, 2001.
} 
ativamente no desdobramento da obra, que passa a ser não apenas o objeto depositado pelo artista no ambiente da galeria, mas também a experiência estética vivida pelo indivíduo que interage com ele.

O trabalho de Teresinha Soares - Ela me deu bola - consistiu em três camas com cores que remetem a times de futebol, sobre as quais os espectadores poderiam se deitar, interagindo com a proposição. Já Umberto Costa Barros aproveitou o espaço em obras do subsolo do Palácio das Artes para sua instalação. Lá ele empilhou tijolos, pedestais, escadas e diversos outros itens encontrados no local e usados habitualmente em construções. Dilton Araújo, por seu turno, depositou apenas uma caixa de fósforos na galeria junto à expressão "uma possibilidade". ${ }^{7}$ Dileny Campos instalou duas placas de sinalização na porta de entrada do Palácio das Artes, sendo que a placa com a palavra "paisagem" apontava para a rua e a outra, com o termo "sub paisagem", apontava para baixo: o subsolo do espaço expositivo, conforme descreve Rodrigo Vivas Andrade. ${ }^{8}$ Frederico Morais atenta para o fato de Labirinto Linear, de Franz Weissmann, ser a concretização da ideia do referido artista a respeito da escultura como um desenho no espaço.

Percebemos em comum a todos esses trabalhos um rompimento com a ideia tradicional de obra, como algo "ensimesmado" e acabado. As propostas dos artistas citados estão abertas à participação do espectador de forma que incitam nele a busca pela legítima vivência da experiência estética. O público, ao sair de seu status de passividade, torna-se elemento ativo do ato criador não apenas quando é convidado pelo artista a interagir com o trabalho artístico, como no caso das Caixas Olfativas ou de Ela me deu bola, mas também quando a ele é permitida - e nele é instigada - a participação na construção dos discursos possíveis para a obra, algo estimulado pelo organizador das exposições, Frederico Morais, com sua ideia de crítica criativa e aberta às narrativas do artista e do público, atores fundamentais na atribuição de sentido à obra de arte no contexto do mundo pós-moderno.

\section{Do corpo à terra}

Como mencionamos, Do Corpo à Terra ocorreu entre 17 e 21 de abril de 1970. Foi uma exposição de arte pública que contou com happenings de artistas da vanguarda dos

\footnotetext{
7 MORAIS, F. Do corpo à terra...

${ }^{8}$ ANDRADE, Rodrigo Vivas. A vanguarda passou por BH: o mito da irradiação e ressonância. Vis, v.13, n.1, 2014, p. 180.
} 
anos 1960/70. Os trabalhos nela apresentados tiveram um caráter mais radical e engajado. Aqui a ideia não parecia ser mais o objeto como "uma nova situação existencial do homem", conforme pensava Frederico Morais $^{9}$, quem, aliás, diz que tal noção pautou ambos os eventos aqui estudados. Em Do Corpo à Terra a questão da arte desmaterializada aparenta ser uma noção mais presente.

É válido destacar o papel importante da mostra como um importante espaço para o surgimento e a afirmação da primeira geração de artistas conceituais brasileiros. Esta, chamada pelo crítico Francisco Bittencourt de "geração tranca-ruas" por seu caráter contestatório e engajado, tornou Do Corpo à Terra "um marco radical na arte brasileira"10, tal como diz o título da exposição posterior sobre a mostra a respeito da qual dissertamos. No entanto, nem todos os artistas participantes gostaram do título dado por Bittencourt: Hélio Oiticica teria refutado sua participação em Do Corpo à Terra devido a isso, renegando sua obra Trilha de Açúcar, feita em parceria com Lee Jaffe, segundo relata Frederico Morais. ${ }^{11}$

Acerca de Morais, é notória a importância de suas ideias como crítico de arte para as questões trazidas à tona pela exposição. A noção de uma Nova Crítica, aberta aos múltiplos discursos dos diferentes agentes participantes do processo criativo, incluindo aqui o espectador, permeou as duas mostras. A noção de obra como algo fechado à participação foi contestada em favor de uma arte participativa. Para Morais, o conceito tradicional de obra não mais valia para a nova arte que surgia naquele momento. Ela teria se libertado de sua existência física e dos limites impostos pela parede e pelo chão, transformando-se em "situação". O artista, nesse sentido, é um propositor de situações a serem experimentadas. ${ }^{12}$

Além disso, a Nova Crítica de Morais, defensora da nova arte de vanguarda, permitia ao crítico atuar em múltiplas frentes, metamorfoseando-se ora em artista ora em organizador de exposições (curador). Consoante Morais, foi em Do Corpo à Terra que um crítico atuou pela primeira vez concomitantemente como artista e curador. A curadoria passava então a ser vista como uma extensão da atividade do crítico-artista. ${ }^{13}$

\footnotetext{
${ }^{9}$ MUSEU DE ARTE DA PAMPULHA (Belo Horizonte, MG). Neovanguardas: catálogo. [Belo Horizonte]: Rona, [2008], p. 48.

10 MORAIS, F. Do corpo à terra...

11 REIS, P. Exposições de arte...

12 MORAIS, F. Artes plásticas: a crise da hora atual. Rio de Janeiro: Paz e Terra, 1975, p. 45.

13 MORAIS, F. Do corpo à terra...
} 
Morais expôs, como crítico-criador, a proposta Quinze Lições de Arte e História da Arte - apropriações: homenagens e equações em Do Corpo à Terra, seu primeiro trabalho nesse sentido. Ela consistiu na instalação de quinze placas contendo fotografia e texto em diversos locais do Parque Municipal de Belo Horizonte. As imagens de diversos pontos do parque dialogavam tanto com a paisagem urbana dos lugares onde foram instaladas quanto com suas legendas, as quais faziam referências a artistas, tendências artísticas e noções pertinentes à história da arte e à arte do momento.

Abaixo transcrevemos as legendas presentes em cada placa do trabalho de Morais:

1. Arqueologia do urbano - escavar o futuro; 2. Arte cinética: não é o que se move, mas a consciência da instabilidade do real; 3. A arte não deixa traços; 4. Homenagem a Bachelard: "imaginar é sempre maior que viver". Imagino, logo, existo; 5. Homenagem a Brancusi - coluna infinita; 6. "Kitsch" = resíduo da arte $=$ arte - resíduo de "kitsch"; 7. Arte total = inespecificidade de todas as artes; 8. Homenagem a Breton - desarrumar o quotidiano com a "fabricação e o lançamento em circulação de objetos aparecidos em sonho", com a "missão de retificar contínua e vivamente a lei, quer dizer, a ordem."; 9. Homenagem a Duchamp - "O homem sério nada coloca em questão. Por isso ele é perigoso. É natural que se faça tirano". "A inconsequência é a fonte de tolerância."; 10. Homenagem a Schwitters - estética do lixo e do precário; 11. Arte $=$ tensionar o ambiente. Tensionar o ambiente - treinar a percepção. Arte $=$ exercícios perceptivos; 12 . Contra-arte/contra-natureza - Onde a arte? Onde a natureza?; 13. Homenagem a Malevich: "o mundo branco da ausência dos objetos"; 14. Homenagem a Tiradentes: "Arte = liberdade": inscrição na parede externa do MAM do Rio; 15. Homenagem a Mondrian: quando a vida tiver equilíbrio não teremos necessidade de pinturas e esculturas. Tudo será arte. A morte da vida é a vida da arte. Arte $=$ vida ${ }^{14}$

Segundo Morais ${ }^{15}$, sua intenção com tal proposta era se apropriar das áreas fotografadas, além de fazer o público pensar nessas áreas como quadros e no Parque Municipal como sua sala de exposições. Morais desloca, assim, o espaço expositivo para o ambiente público, para além dos muros do museu e da galeria, rumo à cidade e à vida cotidiana, ideia defendida por ele em seu Manifesto Do Corpo à Terra, distribuído ao público visitante das duas exposições e publicado no jornal Estado de Minas. ${ }^{16}$ Nele o crítico diz que é a rua o ambiente das experiências fundamentais do ser humano, devendo o museu considerá-la como sua extensão e levar suas atividades para o lado de fora. ${ }^{17}$ Além

\footnotetext{
${ }^{14}$ MUSEU DE ARTE DA PAMPULHA (Belo Horizonte, MG). Neovanguardas...

${ }^{15}$ RIBEIRO, M. A. Neovanguardas..., p. 176.

16 RIBEIRO, M. A. Neovanguardas..., p. 299.

17 MUSEU DE ARTE DA PAMPULHA (Belo Horizonte, MG). Neovanguardas..., p. 46.
} 
disso, ele reflete sobre as drásticas mudanças que vinham ocorrendo no campo da arte, como a ruptura com ideias conservadoras e tradicionalistas, e a necessidade de abertura ao novo.

Participaram de Do Corpo à Terra os seguintes artistas: Hélio Oiticica, Artur Barrio, Cildo Meireles, Lee Jaffe, Lotus Lobo, Luiz Alphonsus, Eduardo Ângelo, José Ronaldo Lima, Luciano Gusmão, Alfredo José Fontes, Dilton Araújo e Décio Noviello, além do já citado Frederico Morais, que atuou como crítico-artista. Lee Jaffe foi à região da Serra do Curral depositar uma trilha de açúcar no local, com o desejo de vê-la se desfazer pela ação das formigas, como uma ação humana se integrando à natureza. Contudo, a Serra do Curral, considerada símbolo natural da cidade para os belo-horizontinos, era explorada por companhias mineradoras para a extração de minério de ferro. Assim, as máquinas revolveram o terreno, destruindo o caminho de açúcar. Consoante Morais (apud REIS, 2005), Jaffe seria o executor de uma proposta de Hélio Oiticica, fato contestado por Oiticica, quem em correspondência enviada à Lygia Clark disse que a autoria da dita intervenção é exclusiva de Lee Jaffe. Morais, por sua vez, relata que a rejeição de Oiticica se deu justamente pela alcunha "geração tranca-ruas" dada por Bittencourt ao grupo de artistas integrantes de Do Corpo à Terra.

Outra artista que apresentou um trabalho com viés ecológico foi Lotus Lobo. Sua ideia de construir um canteiro, ao plantar sementes de milho para observá-las "crescendo e florindo em um lugar inusitado" 18 e integrando-se ao ambiente, infelizmente, não teve êxito. Isso porque a artista, como ela própria afirma, não possuía conhecimentos suficientes sobre agricultura. A concretização da proposta foi também atrapalhada pela polícia, que inclusive a ameaçou.

Artur Barrio depositou "trouxas ensanguentadas" - compostas por sangue, carne, ossos e outros materiais precários - na região do ribeirão Arrudas, local poluído onde, com frequência, eram encontrados corpos de pessoas assassinadas. "Situação T/T1" foi a proposta do artista para o evento, e consistiu em três etapas: a preparação das trouxas em ambiente fechado, a instalação delas às margens do Arrudas e uma ação realizada com papel higiênico. O depósito das trouxas ensanguentadas, especificamente, causou grande alvoroço no local, chamando atenção da polícia e do corpo de bombeiros. O artista, oculto

\footnotetext{
18 RIBEIRO, M. A. Neovanguardas..., pp. 222-223.
} 
em meio à multidão de cinco mil pessoas que foi ao local, aproveitou para registrar o incidente.

Cildo Meireles apresentou o ritual Tiradentes: totem-monumento ao preso político, para o qual queimou 10 galinhas vivas e presas a um mastro encimado por um termômetro. A performance, claramente relacionada à tortura e ao assassinato de presos políticos pela Ditadura - comparados ao herói inconfidente Tiradentes -, foi criticada por Mari'Stella Tristão, diretora do Palácio das Artes e uma das responsáveis pelos dois eventos, que a julgou como um episódio lamentável em um jornal local.

Outra proposta de caráter engajado mostrada na manifestação foi a intervenção de Eduardo Ângelo, que espalhou pelo Parque Municipal, cobrindo parte de sua área gramada, jornais com manchetes sobre a violência política e os desaparecidos nas prisões, em uma alusão direta à repressão imposta pelos militares no País.

O sociólogo e artista mineiro José Ronaldo Lima apresentou um trabalho de caráter conceitual, de modo diferente da proposta sensorial exposta em Objeto e Participação. A intervenção de José Ronaldo Lima, chamada Gramática Amarela, se deu sobre um trecho do gramado e da área calçada para pedestres do Parque Municipal de Belo Horizonte. 0 artista interferiu no local ao grafitar os termos "(ver)melha" e "(grama)tica". Somou a isso jornais cujas manchetes destacavam a Revolução Cultural Chinesa e a Guerra do Vietnã. De visível teor político, o trabalho enaltecia o sistema marxista como alternativa frente ao governo ditatorial dos militares, alinhado ao polo capitalista, e denunciava os abusos cometidos no Vietnã, em uma guerra causada pelo confronto entre esses dois sistemas.

Houve também, nesse trabalho, algo que o aproximava bastante das pesquisas conceituais internacionais: o uso da linguagem escrita. Seja por meio do material impresso, seja através do grafite, a palavra na proposta de Lima se manifesta tanto pelo aspecto cognitivo dos termos utilizados quanto por seu teor perceptivo. 0 jogo linguístico "(ver)melha", escrito com tinta spray da mesma cor descrita pela palavra, figura formalmente, por um lado, tal como um poema concreto: a palavra é fragmentada pelo artista para salientar sua multiplicidade de significados.

José Ronaldo Lima ainda coordenou um happening em homenagem a José Narciso, que faleceu na época. Ele consistiu numa procissão pelas ruas de Belo Horizonte e contou com a participação de Lima e dos demais artistas de Do Corpo à Terra. O caminho 
percorrido abrangeu desde a casa de Narciso até o Palácio das Artes, dentro do Parque Municipal, onde aconteciam os eventos relacionados à Semana de Arte de Vanguarda. Durante esse percurso, os artistas acenderam velas em memória do colega falecido.

Outro artista presente em Do Corpo à Terra foi o pintor Décio Noviello. Na manifestação, todavia, ele apresentou um happening, no qual explodiu granadas sinalizadoras coloridas. A apropriação do espaço local através de tal atividade foi, muito provavelmente, uma proposta híbrida de pesquisa sensorial e trabalho processual. Podese dizer que a pintura de Noviello, libertando-se dos limites do objeto de arte, preencheu o espaço público e esvaiu-se gradativamente até se dissipar por completo, como a fumaça liberada pelas granadas. A efemeridade da ação, seu aspecto fortemente temporal e espacial, parece salientada pelo uso da cor. Talvez, divergindo da análise de Paulo Reis ${ }^{19}$ que considera esse happening apenas em seus aspectos formalistas -, essa "obra" gere, potencialmente, uma reflexão acerca da desmaterialização do objeto artístico.

Essa possível analogia entre o binômio pensamento/linguagem e a fumaça, provavelmente, uma metáfora do etéreo, pode ser interpretada como uma defesa da crença na transcendência do sensível rumo ao inteligível. Contudo, a materialidade da massa pictórica da fumaça pode também evidenciar um ponto de vista diverso do anterior: tal aspecto sensível e sua forte presença como processo no tempo-espaço podem indicar uma ênfase na vida como terreno da experiência, da miscelânea indissociável entre a matéria e a ideia.

Entretanto, a proposta de Noviello também contém uma forte conotação política, mesmo que essa não fosse a intenção do artista, a contar pelo momento histórico no qual ele detonou tais granadas, visto que esse tipo de ação, por parte das Forças Armadas, era habitual nas ruas das grandes cidades brasileiras durante o período da ditadura. Sendo assim, apesar da ligação de Noviello com o Exército - ele era tenente-coronel -, seu trabalho pode ser interpretado também como uma crítica aos abusos de poder do regime totalitário que governou o País na época.

Acrescenta-se ainda que a ligação de Noviello com dois grupos ideologicamente antagônicos (os artistas experimentalistas e os militares) punha-o em uma difícil situação. ${ }^{20}$

\footnotetext{
19 REIS, P. Exposições de arte: vanguarda e política entre os anos 1965 e $1970 . . .$, p. 193.

20 RIBEIRO, M. A. Neovanguardas..., p. 238.
} 
Se, de um lado, Noviello era visto com desconfiança por alguns membros do Exército, por se envolver com os "baderneiros" - tal como os artistas eram chamados pelos militares -, de outro, ele sofria julgamento semelhante por parte desses mesmos artistas, já que ele poderia ser um espião infiltrado no grupo para delatar prováveis opositores do regime.

A questão foi relatada em depoimento à pesquisadora Marília Andrés Ribeiro por Décio Noviello:

Eu tinha que esconder a minha identidade. Foi um problema dos dois lados. Os coronéis do Exército me estranhavam porque eu andava com os baderneiros, e os artistas me olhavam com certa desconfiança por eu pertencer ao agente de repressão. ${ }^{21}$

Dilton Araújo realizou um happening envolvendo o lançamento de pedras de cal sobre o gramado do parque. Esses projéteis foram lançados tal como granadas, em uma ação que interferiu visualmente no espaço do Parque Municipal, colorindo-o de branco. Mais uma vez, pode-se pensar na reflexão crítica a respeito da linguagem da pintura como um dos elementos relevantes de uma das propostas apresentadas. Prosseguindo com essa hipótese, acredita-se em uma tentativa de transformar os paradigmas tradicionais da pintura, ao incluí-la no espaço público como acontecimento. Além disso, observa-se uma conotação política relativa à situação proposta por Araújo, em consonância com o caráter de denúncia de muitas das performances realizadas em Do Corpo à Terra.

Há também uma breve citação de Frederico Morais relativa à outra proposta de Dilton Araújo para Do Corpo à Terra. Conforme o organizador da manifestação, Araújo cercou o terreno do Parque Municipal com uma corda. ${ }^{22}$ Assim, o artista teria se apropriado não apenas do parque, mas de todo um conjunto significativo, incluindo, em seu trabalho, o próprio evento do qual participava, obras, público, artistas, funcionários, passantes e, metaforicamente, a própria instituição museológica, já que o Palácio das Artes se localiza dentro da área do parque. Enfim, uma apropriação do sistema da arte.

Ademais, é possível acrescentar ainda o questionamento de Araújo, por meio desse happening, à grave situação política pela qual o país passava com a intensificação da repressão, principalmente depois de ser instaurado o Ato Institucional № 5. Nesse sentido,

\footnotetext{
21 RIBEIRO, M. A. Neovanguardas..., p. 238.
}

22 MORAIS, F. Artes plásticas..., p. 104. 
o fato de um artista cercar um local público, num período histórico caracterizado pela censura e por constantes interdições nas manifestações mais experimentais no campo da cultura, pode ser interpretado como um ato de ironia em relação a esse poder repressor.

Luciano Gusmão foi um dos artistas brasileiros que mais se valeu em seu discurso artístico de reflexões com fundamentos ecológicos, aproximando-se da land art. Em Do Corpo à Terra, ele realizou duas instalações: Reflexões e Transpiração. Nesta última, Gusmão interferiu na paisagem adicionando sobre a grama um pedaço de plástico. Seu intuito foi o de pesquisar o processo físico transformador pelo qual o conjunto plástico/grama passaria. A transpiração daquele pedaço de grama coberta, evidenciada pelas gotículas encontradas no plástico, enfatizou questões como o caráter de organismo vivo e transitório da natureza, e as relações de interação entre essa e a interferência humana. A paisagem apropria-se do que é depositado nela, transformando-se.

Em Reflexões, Gusmão caminhou com um espelho no local da exposição para investigar como se manifestaria o fenômeno da reflexão dos diversos objetos que encontraria pelo caminho. Além disso, entre outras ações realizadas, o artista posicionou o espelho de modo que esse refletisse o ribeirão Arrudas. Em seguida, lançou pedras no rio, olhando para sua imagem refletida no mesmo espelho. Dessa maneira, Luciano Gusmão apropriava-se tanto de objetos quanto da natureza e de seu reflexo, discutindo a questão do real e de sua imagem nos âmbitos da percepção e do conceito ${ }^{23}$.

Vale salientar ainda a participação, em Do Corpo à Terra, do artista Alfredo José Fontes, cujo trabalho apresentado na mostra carece de informações. Luiz Alphonsus, por seu turno, integrou o corpo de artistas da manifestação com Napalm. Ao queimar, sobre o gramado do local, uma faixa de plástico de 15 metros, o artista imprimiu na grama um registro de sua ação. O trabalho fazia alusão direta ao impacto causado pela bomba napalm, utilizada na Guerra do Vietnã, pelo exército estadunidense. A guerra imprimiu tanto nos corpos quanto no espaço geográfico e no imaginário dos vietnamitas um registro da violência como ferramenta opressora. De maneira semelhante, o happening de Alphonsus, explicitamente político e contestador, demarcou o percurso de sua ação no tempo e no espaço sobre o terreno do Parque.

\footnotetext{
${ }^{23}$ RIBEIRO, M. A. Neovanguardas..., p. 231.
} 
As pretensões intrínsecas às propostas da manifestação Do Corpo à Terra (e ao evento em si, principalmente) de transformação do sistema da arte no Brasil são reflexos da situação vivida à época pelos grupos de resistência à ditadura e compartilhada pelos participantes do evento. Como combustível para a contestação do poder repressor estabelecido (tanto no âmbito sociopolítico quanto no da arte), o pensamento norteador evidente em tal manifestação, longe de ser acrítico, fomentou o debate acerca de questões tabus. E isso sob o risco da tortura e da morte para os artistas participantes do evento, dada a vigência, à época, da Ditadura Militar em seu período mais opressor. De modo semelhante às guerrilhas, capazes de desestruturar sistemas cristalizados, Do Corpo à Terra interveio na conjuntura artística do País de maneira relevante e audaz, contribuindo, assim, para a (re)significação da ideia de arte no panorama da pós-modernidade e para a afirmação da experiência estética do espectador.

\section{A experiência estética em Objeto e participação e Do corpo à terra}

O filósofo estadunidense John Dewey realizou 10 conferências em Harvard, em 1931. Estas resultaram eu seu notável livro Arte como Experiência, o qual teremos como base para nossas reflexões. Para Dewey ${ }^{24}$, a ideia atual de arte a toma como algo apartado da experiência humana, posta em um pedestal distante do espectador, contrariando sua própria natureza como coisa que está imersa no âmbito da experiência. Isso se daria com objetos de arte que atingiram o status de clássico, os quais se afastariam de seu contexto de origem. Tal fato demonstra como a arte se tornou uma área à parte das demais formas de realização humanas. ${ }^{25}$

A arte, como forma refinada e intensificada da experiência, deveria voltar-se novamente à vida cotidiana, reconhecendo-se e sendo reconhecida uma vez mais como elemento integrante da experiência humana. De acordo com o filósofo ${ }^{26}$, a compreensão da experiência estética precisa iniciar com os eventos cotidianos que prendem o olhar, os quais seriam sua manifestação em forma bruta. $O$ autor prossegue contrapondo dois exemplos: o mecânico inteligente, afeiçoado às suas ferramentas e, portanto, artisticamente engajado; e o mecânico descuidado, aquele que não compartilha tal estado

\footnotetext{
24 DEWEY, John. Arte como experiência. São Paulo: Martins Fontes, 2010, p. 59.

25 DEWEY, John. Arte como experiência..., pp. 59-60.

26 DEWEY, John. Arte como experiência..., p. 61.
} 
com o primeiro. ${ }^{27} \mathrm{O}$ prazer seria, então, elemento intrínseco à arte como experiência. Porém, se a arte aparenta ser algo sem vitalidade para as pessoas comuns, a "fome estética" 28 as impulsiona a procurar o vulgar e o barato para suprir suas necessidades estéticas.

A arte em sua origem está ligada à vida cotidiana dos povos que a criaram em contraposição à realidade apartada dos museus e galerias. ${ }^{29} \mathrm{~A}$ atual segregação da arte em relação à experiência seria fruto do mundo moderno ${ }^{30}$, pois a ascensão da noção da instituição museológica como promotora da ideia da separação entre arte e vida estaria conectada ao crescimento do sistema capitalista. ${ }^{31}$

Diante de tal conjuntura, é necessário "recuperar a continuidade da experiência estética com os processos normais do viver". ${ }^{32}$ Afirma Dewey que uma experiência genuína, mesmo que tosca, está mais próxima da experiência estética que um objeto apartado da vida comum. A experiência intensifica a vitalidade. Nesse sentido, ela ultrapassa o âmbito dos sentimentos e das sensações particulares do indivíduo para se tornar "uma troca ativa e alerta com o mundo". ${ }^{33}$ São fatores que atrapalham a experiência estética: a monotonia, a desatenção e a submissão às convenções. ${ }^{34}$

Tanto em Objeto e Participação como em Do Corpo à Terra houve uma evidente preocupação com a experiência estética do espectador. Em ambas as mostras a diluição da arte na vida e sua interação com o espectador foram evidentes. O próprio título de Objeto e Participação indica a tônica da exposição: a colaboração do público no ato criador, como elemento fundamental no desenrolar da obra, por meio da experiência estética. Tal ideal era compartilhado por muitos dos artistas participantes e pelo organizador da exposição, Frederico Morais, que o abordou em sua produção escrita. ${ }^{35}$

O crítico defendia com veemência a participação do espectador nos desdobramentos do trabalho artístico, questão já presente na Declaração de Princípios Básicos da Vanguarda, de 1967, da qual foi um dos signatários, junto ao também crítico

\footnotetext{
27 DEWEY, John. Arte como experiência..., pp. 62-63.

28 DEWEY, John. Arte como experiência..., p. 64.

29 DEWEY, John. Arte como experiência..., p. 65.

${ }^{30}$ DEWEY, John. Arte como experiência..., p. 67.

${ }^{31}$ DEWEY, John. Arte como experiência..., p. 67.

32 DEWEY, John. Arte como experiência..., p. 70.

33 DEWEY, John. Arte como experiência..., p. 83.

34 DEWEY, John. Arte como experiência..., p. 110.

35 MORAIS, F. Artes plásticas..., p. 53-57.
} 
Mário Barata e a diversos artistas, entre os quais, Hélio Oiticica. Este último, aliás, foi uma das principais vozes a respeito de tal temática.

A arte proporciona ao espectador o exercício da liberdade de acordo com Morais, questão suscitada primeiramente pelo também crítico Mário Pedrosa. A arte de vanguarda, por seu caráter experimentalista e aberto, retira o espectador, vítima de um sistema que o reprime, de seu estado alienado, despertando-o para a realidade sociopolítica na qual está inserido e munindo-o de ferramentas para intervir ativamente nela.

Nesse ínterim, obras como os carimbos de Thereza Simões convidam o publico à reflexão, ao questionar o real e o establishement, representado e legitimado pela instituição museológica. A arte como ideia retira o indivíduo do conforto do lugar-comum, instigando-o ao diálogo com o artista, por mais que possa parecer hermética. Quando o espectador aceita dialogar com o artista-propositor, libertando-se de ideias pré-concebidas sobre o que é ou não arte, ele se permite participar do "jogo" da arte, desconstrói verdades e fortalece sua criticidade.

As caixas de José Ronaldo Lima, por seu turno, despertam no público sua experiência sensorial, embaralhando, como já dissemos, a hierarquia dos sentidos. Instiga a participação ativa por meio das sensações, incentiva no espectador a própria experiência do viver: um viver afirmativo, um despertar do corpo para a realidade. As pegadas de Helt sugerem um caminho ao indivíduo, sem imposição. A opção por seguir ou não tais passos cabe à pessoa. E é justamente nessa autonomia de escolha dada a ela que se encontra a participação na proposta de Helt.

Teresinha Soares, com suas camas, propõe a ativação do corpo por meio da interação do espectador com seu trabalho. O labirinto de Weissmann abre-se também à interação com o público. As placas de sinalização de Dileny Campos parecem destacar a rua como âmbito da experiência estética, em detrimento da galeria. Dilton Araújo, com uma reles caixa de fósforos, explora as possibilidades do objeto ao deslocá-lo de sua banalidade e instigar no espectador o exercício imaginativo.

Os happenings de Do Corpo à Terra, por sua vez, radicalizaram a arte a ponto de diluí-la no cotidiano, de modo a inseri-la na realidade não só do público visitante da manifestação, como igualmente de pessoas alheias ao acontecimento. Podemos notar isso em propostas como as trouxas ensanguentadas de Barrio, imersas na realidade da 
população que se aglomerou na região onde foram depositadas de modo chocante. Aqui a experiência estética travestiu-se em escatologia, transformando a arte em instrumento de problematização e tensionamento do real. Tal proposta remete, assim, ao discurso de Dewey sobre os eventos do dia-a-dia como forma bruta da experiência estética.

A proposta de Meireles, de modo semelhante àquela de Barrio, tirou o espectador de sua zona de conforto por meio da violência. Esta, longe de ser gratuita, remetia aos heróis anônimos da resistência à repressão imposta pelo Regime Militar. A participação do espectador, mais uma vez, dava-se pelo sentimento de repulsa, pelo choque, pela agressividade que reproduzia a própria situação política vivida pela sociedade brasileira no momento.

Essa chamada do artista para que o espectador se atente aos fatos da realidade presente, muitos dos quais inacessíveis a ele, vista a instauração da censura aos meios de comunicação pelo governo, também se encontra nas proposições de Eduardo Ângelo, com seus jornais sobre a repressão; na alusão de José Ronaldo Lima à Revolução Cultural Chinesa e à Guerra do Vietnã; nas pedras de cal, lançadas tal como granadas, de Dilton Araújo; na napalm de Luiz Alphonsus; e ainda nos sinalizadores de Noviello - por mais que essa não fosse a intenção inicial do artista.

Outros artistas participantes (como Oiticica, Jaffe, Morais, Lobo e Gusmão), com suas intervenções urbanas, happenings e apropriações, salientaram a cidade e a vida como contextos da arte. Esta, uma vez regressando à sua circunstância original, fora do ambiente institucionalizado, pode se abrir novamente à participação do espectador, provocando nele a experiência estética, intensificando seu viver.

\section{Considerações finais}

Objeto e Participação e Do Corpo à Terra foram não apenas palco para as ações experimentalistas e engajadas da arte de vanguarda do início da década de 1970, como também tiveram o mérito de serem espaços abertos à participação do espectador. Este, não era apenas chamado a dialogar com a obra, intervir nela e ser elemento ativo na construção da rede de discursos que a constitui. Frederico Morais e os artistas de ambas as mostras radicalizam este chamado ao convidar o espectador a ser cocriador de uma proposta que depende dele para que possa se desdobrar em múltiplas possibilidades, 
garantindo, assim, sua existência e permanência como algo relevante e atual. Rompem-se, então, as amarras que impediam o espectador de vivenciar a experiência estética libertadora, somente possível com uma arte que se volte para vida, seu contexto original.

\section{Referências bibliográficas}

AMARAL, A. Arte para quê? São Paulo: Nobel, 1984.

ANDRADE, Rodrigo Vivas. A vanguarda passou por BH: o mito da irradiação e ressonância. Vis, v.13, n.1, 2014 [2015]. Não paginado. Disponível em: <https://www.academia.edu/attachments/37779833/download_file?st=MTU1NzY4MTM 3NSwxNzkuMTgzLjMOLjg3LDI2MjUOMDQ\%3D\&s=swp-toolbar>. Acesso em: 12 maio 2019. ANDRADE, Rodrigo Vivas. Os salões municipais de belas artes e a emergência da arte contemporânea em Belo Horizonte: 1960-1969. 2008. Tese (Doutorado em História) Instituto de Filosofia e Ciências Humanas, Universidade Estadual de Campinas, Campinas, 2008.

ARCHER, M. Arte Contemporânea. São Paulo: Martins Fontes, 2001.

ARGAN, G. Arte e crítica de arte. 2. ed. Lisboa: Estampa, 1993.

BENJAMIN, W. A obra de arte no tempo de suas técnicas de reprodução. In: VELHO, G. (Org.). Sociologia da arte. Rio de Janeiro: Zahar, 1969. v. 4, p. 15-47.

BENJAMIN, W. Pequena história da fotografia. In: Magia e técnica, arte e política. São Paulo: Brasiliense, 1996. v. 1, p. 91-107.

BOSI, Alfredo. Fenomenologia do olhar. In: NOVAES, Adauto (Org.) O olhar. São Paulo: Companhia das Letras, 1988. p.65-86.

CANONGIA, L. O legado dos anos 60 e 70. Rio de Janeiro: Jorge Zahar, 2005.

CAUQUELIN, A. Arte contemporânea. São Paulo: Martins Fontes, 2005.

DANTO, A. Após o fim da arte. São Paulo: Odysseus, 2006.

DUCHAMP, M. O ato criador. In: BATTCOCK, G. A nova arte. 2. ed. São Paulo: Perspectiva, 1986. p. 71-74.

DUNN, Christopher. Nós somos os propositores: vanguarda e contracultura no Brasil, 19641970. Revista ArtCultura, Uberlândia, v. 10, n. 17, p. 143-158, 2008.

FERREIRA, G.; COTRIM, C. (Orgs.). Clement Greenberg e o debate crítico. Rio de Janeiro: Jorge Zahar, 2001.

FERREIRA, G. Escritos de artistas: anos 60/70. Rio de Janeiro: Jorge Zahar, 2006.

FREIRE, C. Poéticas do processo. São Paulo: lluminuras, 1999.

GROSSMANN, M. Do ponto de vista à dimensionalização. Item, Rio de Janeiro, v. 1, n. 3, p. 29-37, 1996.

KRAUSS, R. A escultura no campo ampliado. Revista Gávea, Rio de Janeiro, ano 1, v. 1, n. 1, p. 87-93, 1995.

KRAUSS, R. Caminhos da escultura moderna. São Paulo: Martins Fontes, 1998. 
MARCUSE, H. A arte na sociedade unidimensional. In: LIMA, L. C. (Org.). Teoria da cultura de massa. 7. ed. São Paulo: Paz e Terra, 2005. p. 259-270.

MARCUSE, H. A dimensão estética. São Paulo: Martins Fontes, 1977.

MARCUSE, H. Sobre o caráter afirmativo da cultura. In: Cultura e Sociedade. 2.ed. São Paulo: Paz e Terra, 2006. v. 1, p. 89-137.

MORAIS, F. Artes plásticas: a crise da hora atual. Rio de Janeiro: Paz e Terra, 1975.

MORAIS, F. Artes plásticas na América Latina: do transe ao transitório. Rio de Janeiro: Civilização Brasileira, 1979.

MORAIS, F. Do corpo à terra: um marco radical na arte brasileira. Belo Horizonte, 2001. Catálogo de exposição.

MORAIS, F. Do Corpo à Terra. In: SEFFRIN, S. (Org.). Frederico Morais. Rio de Janeiro: FUNARTE, 2004. p. 115-123.

MUSEU DE ARTE DA PAMPULHA (Belo Horizonte, MG). Neovanguardas: catálogo. [Belo Horizonte]: Rona, [2008]. 163 p. il. Catálogo de exposição.

OBJETO e Participação (1970 : Belo Horizonte, MG). In: ENCICLOPÉDIA Itaú Cultural de Arte e Cultura Brasileiras. São Paulo: Itaú Cultural, 2018.

O'DOHERTY, B. No interior do cubo branco: a ideologia do espaço na arte. São Paulo: Martins Fontes, 2002.

PALHARES, T. H. Aura: a crise da arte em Walter Benjamin. São Paulo: Barracuda, 2006.

PIGNATARI, D. Teoria da guerrilha artística. In: Contracomunicação. 2. ed. São Paulo: Perspectiva, 1973. p. 157-166.

REIS, P. Arte de vanguarda no Brasil. Rio de Janeiro: Jorge Zahar, 2006.

REIS, P. Exposições de arte: vanguarda e política entre os anos 1965 e 1970. 2005. 213 f. Tese (Doutorado em História) - Setor de Ciências Humanas, Letras e Artes, Universidade Federal do Paran, Curitiba, 2005.

RIBEIRO, M. A. Neovanguardas. Belo Horizonte: C/ Arte, 1997.

WOOD, Paul. Arte conceitual. São Paulo: Cosac Naify, 2002.

Recebido em 15 de julho de 2019

Aprovado em 26 de novembro de 2019 